\title{
ORIENTED NUCLEATION IN LOW-CARBON STEELS
}

\author{
R. L. EVERY† and M. HATHERLY \\ School of Metallurgy, University of New South Wales, \\ Kensington, New South Wales, Australia
}

(Received June 29, 1972)

\begin{abstract}
The preferred orientations in hot-rolled, cold-rolled (70\% reduction), and annealed low-carbon steels (capped and aluminium-killed grades) have been investigated. Particular attention has been paid to the factors that control texture formation during annealing.

The elastic energy stored in the cold-rolled steels is orientation dependent and the sequence, estimated from a Fourier analysis of X-ray line broadening, is $V_{110}>V_{111}>V_{211}>V_{100}$; the values range from 3.51 to $1.14 \mathrm{cal} / \mathrm{g}$ atom. The high energy components $(\{110\},\{111\})$ have elongated cell structures but those of lower energy are equiaxed. In capped steels the high energy components recover and recrystallize most rapidly. In aluminium-killed steels both recovery and recrystallization are inhibited at low temperatures $\leqslant 500^{\circ} \mathrm{C}$ and recrystallization begins first in the $\{111\}$ components. It is shown that these effects are associated with precipitation and/or segregation of AlN during recovery. The recrystallization texture is determined primarily by oriented nucleation.
\end{abstract}

\section{INTRODUCTION}

Recent studies $^{1-3}$ have indicated that oriented nucleation determines the range of orientations developed in the early stages of recrystallization and influences the primary recrystallization texture formed in low-carbon steels. Takechi et al. ${ }^{2}$ inferred that the correspondence between the orientation dependence of elastic stored energy in the deformed material and the textural changes that accompany recrystallization provide evidence of an oriented nucleation control of texture formation with nucleation occurring in high energy blocks. No detailed information about the recovery and nucleation processes occurring in cold-rolled steels was presented, however, to substantiate such a mechanism. Furthermore, Matsuo et al. ${ }^{3}$ found that this correspondence applied only for steels having a coarse grain size $(300 \mu \mathrm{m})$ before cold rolling. Dillamore $e t$ al. ${ }^{1}$ have used the orientation dependence of stored energy, determined from electron microscope estimates of subgrain size and misorientation, to predict the textural changes that occur in the early stages of recrystallization. The predicted textural changes are not, however, in complete agreement with those observed experimentally. ${ }^{2-5}$

†Now at Central Research Laboratories, John Lysaght (Australia) Pty. Ltd., Newcastle, Australia.
The present paper describes the orientation dependence of elastic stored energy in cold-rolled low-carbon steels and the effect of this dependence on recovery and recrystallization. The preferred orientations in the steels are considered with particular reference to the textural changes that accompany recrystallization.

\section{EXPERIMENTAL PROCEDURE}

The materials used in the investigation were commercial low-carbon capped and aluminiumkilled steels. Details of gauge, composition, and processing of the hot-rolled steels $(\mathrm{Cl}, \mathrm{K} 1)$ and the corresponding cold-rolled steels $(\mathrm{C} 2, \mathrm{~K} 2)$ are given in Table I. The following annealing treatments were carried out:

i) steels $\mathrm{C} 2$ and $\mathrm{K} 2$ - annealed for various times at $400^{\circ} \mathrm{C}, 500^{\circ} \mathrm{C}, 600^{\circ} \mathrm{C}$ and $700^{\circ} \mathrm{C}$;

ii) steel $\mathrm{K} 2$-annealed 4 hours at $500^{\circ} \mathrm{C}$ prior to heat treatment at $700^{\circ} \mathrm{C}$.

Conventional and inverse pole figure data were used to describe the surface and midplane textures of the hot and cold-rolled steels and the annealed samples. The Schulz ${ }^{6}$ back reflection technique was used for the determination of conventional pole figures. Inverse pole figures were determined using the Harris ${ }^{7}$ method and the normalizing procedure of Horta et al. ${ }^{8}$

The elastic strain energy of the major deformation texture components in the cold-rolled steels 
TABLE I

Materials

\begin{tabular}{|c|c|c|c|c|c|c|c|c|c|c|c|c|c|c|}
\hline Designatior & n Steel Type & $\begin{array}{l}\text { Finishing } \\
\text { Temp. }{ }^{\circ} \mathrm{C}\end{array}$ & $\begin{array}{l}\text { Coiling } \\
\text { Temp. }{ }^{\circ} \mathrm{C}\end{array}$ & $\begin{array}{c}\text { Thickness, } \\
\text { mm. }\end{array}$ & C & $\mathbf{P}$ & Mn & Si & $\mathbf{S}$ & $\mathrm{Cr}$ & $\mathrm{Ni}$ & $\mathbf{C u}$ & Al & Sn \\
\hline $\mathrm{Cl}$ & $\begin{array}{l}\text { capped } \\
\text { hot-rolled }\end{array}$ & 855 & 640 & 2.03 & 0.080 & 0.002 & 0.28 & 0.005 & 0.016 & 0.005 & 0.010 & 0.015 & 0.005 & 0.002 \\
\hline $\mathrm{C} 2$ & $\begin{array}{l}\text { capped } \\
\text { cold-rolled }\end{array}$ & & & 0.64 & 0.080 & 0.002 & 0.30 & 0.005 & 0.016 & 0.005 & 0.015 & 0.015 & 0.005 & 0.002 \\
\hline K1 & $\begin{array}{l}\text { killed } \\
\text { hot-rolled }\end{array}$ & 875 & 610 & 2.44 & 0.055 & 0.002 & 0.29 & 0.020 & 0.016 & 0.020 & 0.020 & 0.020 & 0.050 & 0.002 \\
\hline K2 & $\begin{array}{l}\text { killed } \\
\text { cold-rolled }\end{array}$ & & & 0.89 & 0.055 & 0.002 & 0.30 & 0.020 & 0.016 & 0.020 & 0.020 & 0.020 & 0.050 & 0.002 \\
\hline
\end{tabular}

and the relative rates of recovery of these components during annealing were determined by Fourier analysis of X-ray line broadening. The Stoke's ${ }^{9}$ method of correction for instrumental broadening and the Warren-Averbach ${ }^{\mathbf{1 0 , 1 1}}$ method of separation of particle size and inhomogeneous strain were used. The components studied had $\{100\}$, $\{110\},\{211\}$ and $\{111\}$ planes parallel to the sheet surface and the elastic strain energies, $V_{h k l}$, of these components were estimated from the expression

$$
V_{h k l}=3 / 2 \cdot E_{h k l} \cdot\left\langle\varepsilon_{50}^{2}\right\rangle,
$$

where $E_{h k l}$ is Young's Modulus in the $\langle h k l\rangle$ direction and $\left\langle\varepsilon_{50}^{2}\right\rangle$ is the mean-square-strain over a column length of $50 \AA$. Values of $E_{\text {hkl }}$ were calculated from published data. ${ }^{12}$ The line broadening index, $R^{13-15}$, was determined for the 200, 211, 220 , and 222 reflections from measurements of the separation of the MoK $\alpha$ doublet; the values of $R$ were used to calculate the fraction residual line broadening.

The substructure of the cold-rolled and annealed steels was examined by transmission electron microscopy. Both face sections (perpendicular to the normal direction (ND) of the sheet) and edge sections (perpendicular to either the transverse direction (TD) or the rolling direction (RD) of the sheet) were examined. The foils were prepared by a modified window technique; electro-polishing was carried out using a cooled solution of $5 \%$ perchloric acid and $95 \%$ acetic acid. For edge section foils the sheet was first iron plated to protect the edges during electro-polishing and the plated sample was sectioned by spark machining prior to thinning.

\section{RESULTS}

\section{Preferred Orientations}

The preferred orientations in the hot-rolled, coldrolled and annealed steels can be described in terms of the usual partial fibre textures, $A$ and $C$, where:

$A-$ has a $\langle 110\rangle$ axis in the rolling direction and the rolling plane varies $\{100\}$ to $\{111\}$.

$\mathrm{C}$-has a $\langle 111\rangle$ axis parallel to the normal direction and the rolling direction varies from $\langle 110\rangle$ to $\langle 211\rangle$.

The hot-rolled killed steel, K1, had small (35$40 \mu \mathrm{m}$ ) equiaxed ferrite grains and an essentially random texture that did not vary significantly from the surface to the midplane of the strip; these properties are consistent with a high finishing temperature. ${ }^{2,16-18}$ The properties of the hotrolled capped steel, $\mathrm{Cl}$ were typical ${ }^{2,16-19}$ of a low finishing temperature, viz.: strong textures that varied markedly from $\{110\}\langle u v w\rangle$ at the surface to mixed fibre textures $\mathrm{A}$ and $\mathrm{C}$ at the midplane of the strip and a microstructure that consisted of coarse $(145-150 \mu \mathrm{m})$ equiaxed recrystallized grains and elongated recovered grains. Despite these differences the textures of the cold-rolled steels, K2 and $\mathrm{C} 2$, were similar and consisted of strong $\{100\}\langle 110\rangle,\{211\}\langle 110\rangle$, and $\{111\}\langle 110-211\rangle$ components; the spread about these components was described adequately by partial fibre textures $A$ and $C$. In both steels texture A was developed more strongly at the surface than at the midplane of the sheet; texture $\mathrm{C}$ showed the opposite trend.

The changes in normal direction (ND) axis density during annealing of the cold-rolled steels 


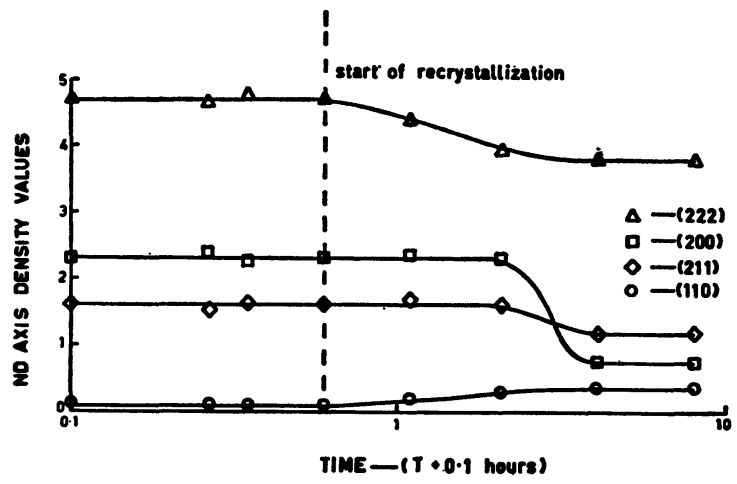

(a)

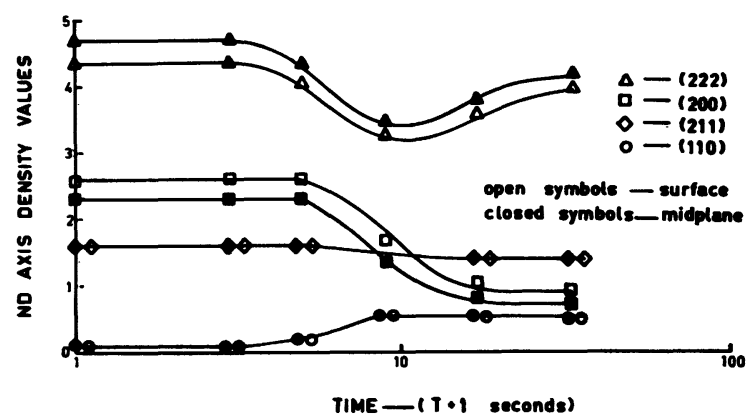

(b)

FIGURE 1 Changes in $N D$ axis density values during annealing of steel $\mathrm{C} 2$ at (a) $500^{\circ} \mathrm{C}$, (b) $700^{\circ} \mathrm{C}$.

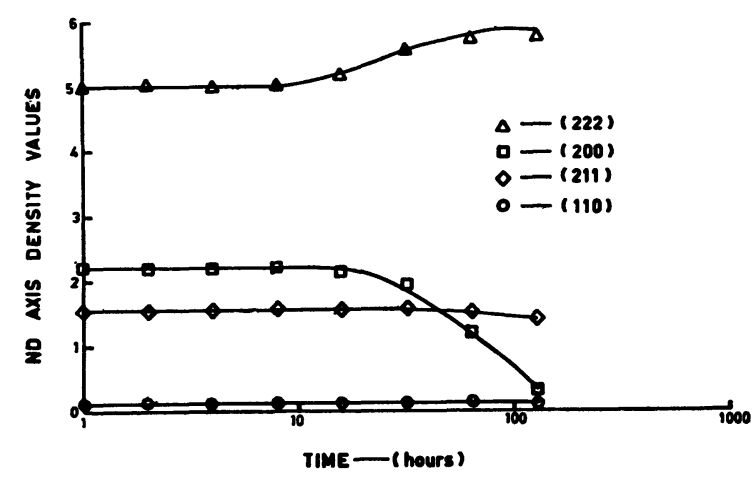

(a)

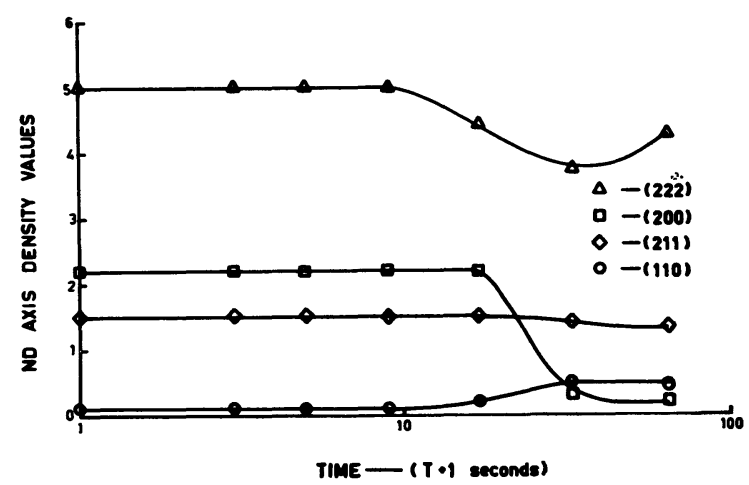

(b)

FIGURE 2 Changes in $N D$ axis density values during annealing of steel $\mathrm{K} 2$ at (a) $500^{\circ} \mathrm{C}$, (b) $700^{\circ} \mathrm{C}$ after a recovery anneal of $4 \mathrm{hr}$ at $500^{\circ} \mathrm{C}$.

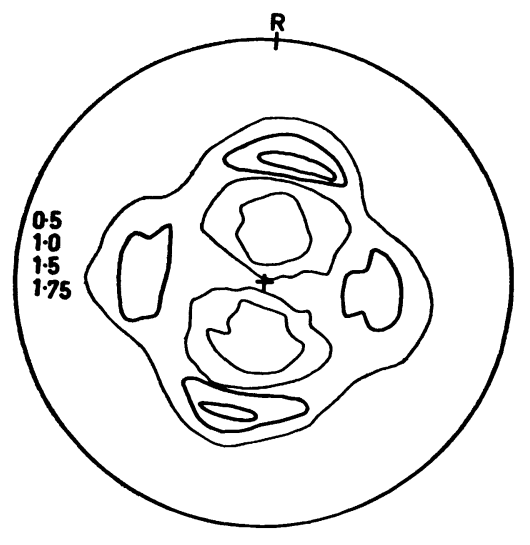

(a)

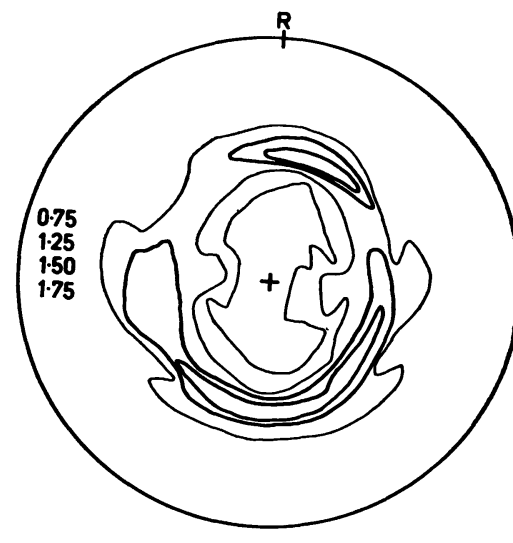

(b)

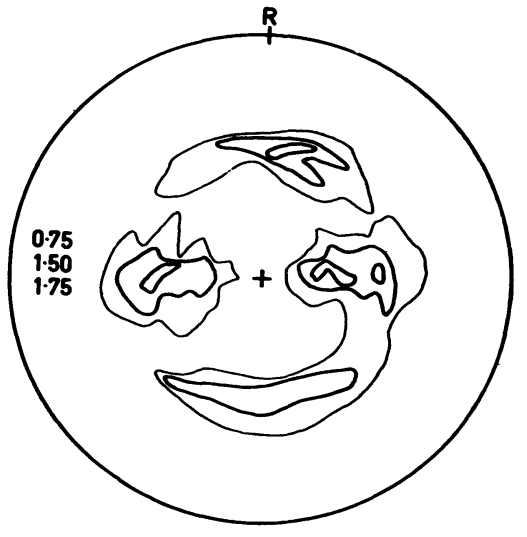

(c)

FIGURE 3 (200) pole figures showing the midplane textures of: (a) steel C2 annealed $8 \mathrm{hr}$ at $500^{\circ} \mathrm{C}$; (b) steel $\mathrm{K} 2$ annealed $128 \mathrm{hr}$ at $500^{\circ} \mathrm{C}$; and $(c)$ steel $\mathrm{K} 2$ recrystallized at $700^{\circ} \mathrm{C}$ after a recovery treatment of $4 \mathrm{hr}$ at $500^{\circ} \mathrm{C}$. 
are given in Figures 1 and 2. The primary recrystallization texture of steel $\mathrm{C} 2$ was not affected markedly by variations in the annealing cycle and a typical (200) pole figure is shown in Figure 3a; the high intensity regions are described adequately by partial fibre texture $C$. In the killed steel, the recrystallization texture was affected significantly by variations in the annealing cycle. At $500^{\circ} \mathrm{C}$ fibre texture $\mathrm{C}$ was developed strongly (Figure $3 \mathrm{~b}$ ), but at $700^{\circ} \mathrm{C}$ the texture was essentially the same as that formed in steel $\mathrm{C} 2$ (Figure 3a). A recovery anneal at $500^{\circ} \mathrm{C}$ prior to recrystallization at $700^{\circ} \mathrm{C}$ developed the texture shown in Figure 3c.

\section{X-ray Line Broadening Measurements}

Values of effective particle size $\left(D_{E}\right)$, root mean square strain $\left(\left\langle\varepsilon_{50}^{2}\right\rangle^{\frac{1}{2}}\right)$, and elastic stored energy $\left(V_{h k l}\right)$ for the cold-rolled steels $\mathrm{C} 2$ and $\mathrm{K} 2$ are of elastic Table II. For both steels the sequence given in stored energy was

$$
V_{110}>V_{111}>V_{211}>V_{100} \text {. }
$$

The changes in residual line broadening and elastic strain energy that occurred during annealing of the steels at $500^{\circ} \mathrm{C}$ are shown in Figures 4 and 5

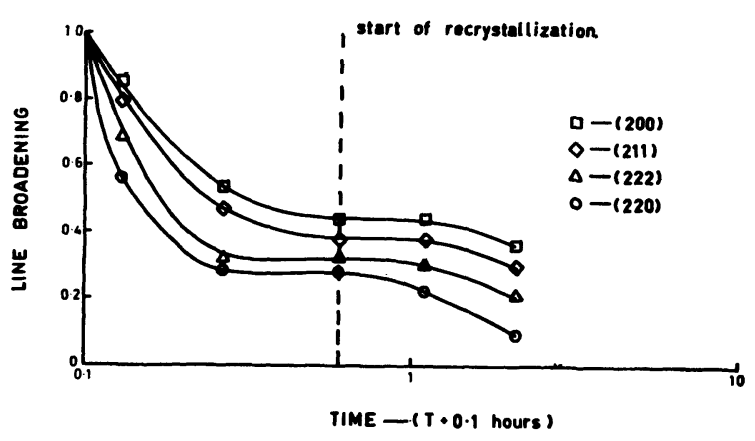

(a)

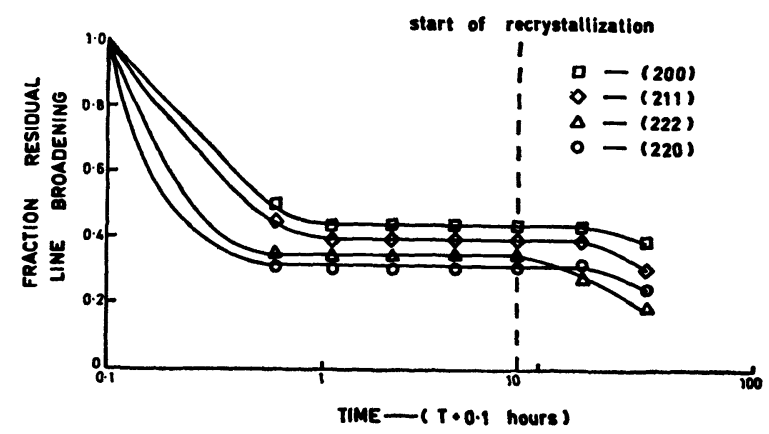

(b)

FIGURE 4 Changes in X-ray line broadening during annealing at $500^{\circ} \mathrm{C}$ of $(a)$ steel $\mathrm{C} 2,(b)$ steel K2.

TABLE II

Fourier analysis of cold-rolled steels

\begin{tabular}{|c|c|c|c|c|c|}
\hline \multirow{2}{*}{ Sample } & \multirow{2}{*}{ Measurement } & \multicolumn{4}{|c|}{ Component } \\
\hline & & $\{110\}$ & $\{111\}$ & $\{211\}$ & $\{100\}$ \\
\hline \multirow{3}{*}{$\begin{array}{l}\text { Steel C2-as rolled, } \\
\text { ND sample } \\
\text { (midplane) }\end{array}$} & $D_{E}-\AA$ & 500 & 350 & 350 & 350 \\
\hline & $\left\langle\varepsilon_{50}^{2}\right\rangle^{\frac{1}{2}} \times 10^{3}$ & 2.50 & 1.70 & 1.50 & 1.80 \\
\hline & $V-\mathrm{cal} / \mathrm{g}$ atom & 3.51 & 2.09 & 1.27 & 1.14 \\
\hline \multirow{3}{*}{$\begin{array}{l}\text { Steel } \mathrm{K} 2 \text { as rolled } \\
\text { ND sample } \\
\text { (midplane) }\end{array}$} & $D_{E}-\AA$ & 450 & 250 & 350 & 300 \\
\hline & $\left\langle\varepsilon_{50}^{2}\right\rangle^{\frac{1}{1}} \times 10^{3}$ & 2.40 & 1.70 & 1.70 & 1.85 \\
\hline & $V-\mathrm{cal} / \mathrm{g}$ atom & 3.23 & 2.09 & 1.62 & 1.15 \\
\hline
\end{tabular}




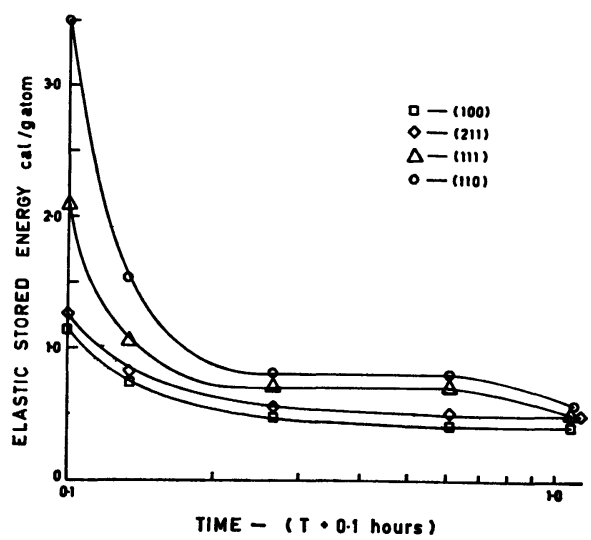

(a)

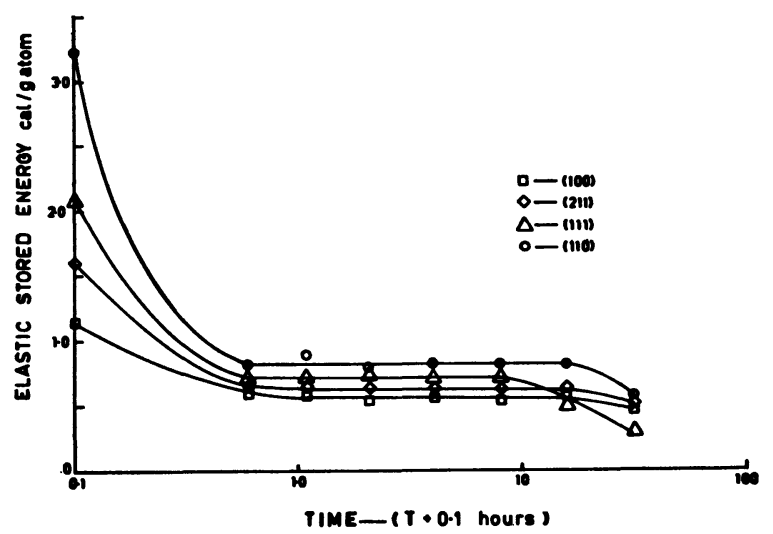

(b)

FIGURE 5 Changes in elastic stored energy, $V_{h k l}$, during annealing at $500^{\circ} \mathrm{C}$ of $(a)$ steel $\mathrm{C} 2$, (b) steel $\mathrm{K} 2$.

respectively. Steel $\mathrm{C} 2$ recovered more rapidly than steel $\mathrm{K} 2$ but the relative rates of recovery of the four texture components were unaltered; $R_{110}>R_{111}$ $>R_{211}>R_{100}$ and the $\{110\}$ and $\{111\}$ components reached a state of maximum recovery before the $\{211\}$ and $\{100\}$ components.

The recrystallization behaviour of the two steels was different and recrystallization was inhibited markedly in steel K2 (cf. Figures 4a, 4b). The $\{110\}$ and $\{111\}$ components recrystallized first in steel $\mathrm{C} 2$ and the $\{111\}$ component first in steel $\mathrm{K} 2$.

\section{Electron Microscopy}

The cell structures of the cold-rolled steels belonged to two general groups. The predominant group consisted of cells that were elongated in both the transverse and rolling directions (Figures 6a, 6b respectively). The thickness was $0.15-0.20 \mu \mathrm{m}$ and the dimensions parallel to the transverse and rolling directions were approximately 2-3 times greater. In these cells the rolling plane was within $\sim 10^{\circ}$ of $a\langle 110\rangle$ zone and between $\{110\}$ and $\{111\}$ (Figure 7a). The frequency of observation of $\{110\}$ $\langle u v w\rangle$ material was greater than would have been expected from X-ray density measurements $\left(I_{110}\right.$ $\sim 0.07 R)$. It seems probable that material of this orientation thinned preferentially during electropolishing.

The second group consisted of approximately equiaxed cells (Figure 6c, 6d), with average diameter $0.30-0.45 \mu \mathrm{m}$; the rolling plane was within $30^{\circ}$ of $\{100\}$, see Figure 7a. Generally, the cell structure within a particular grain was uniform, and belonged to one or other of the two groups but some grains contained cells of both types. The dislocation distribution in the elongated cells was not constant; uniform distributions of dislocations, clearly defined dislocation networks or definite substructures were all observed.

During the early stages of recovery similar structural variations were observed in both steels. Elongated and equiaxed subgrains were developed with orientations (Figure 7b) similar to those of the corresponding cell types in the cold-rolled structures. On further annealing subgrain growth occurred in steel C2 and this was more pronounced in the regions that had previously consisted of elongated subgrains. As growth proceeded the elongated subgrains became more equiaxed but growth of the lower energy $\{211\}$ and $\{100\}$ components was not apparent until longer times at temperature. In steel $\mathrm{K} 2$ there was a marked inhibition of subgrain growth and after 32 hours at $500{ }^{\circ} \mathrm{C}(10 \%$ recrystallization) the only evidence of growth was in regions of elongated subgrains. After 5\% recrystallization the recrystallized grains in steel C2 had the orientations $\{111\}\langle u v w\rangle$, $\{110\}\langle u v w\rangle$, and $\{311\}\langle u v w\rangle$. The most commonly observed relationships between the recrystallized grains and the recovered matrix material were:

i) $\{111\}\langle u v w\rangle$ recrystallized grains growing into $\{111\}\langle u v w\rangle$ matrix material; the orientation difference consisted of a rotation of $10-20^{\circ}$.

ii) $\{110\}\langle u v w\rangle$ recrystallized grains growing into $\{110\}\langle u v w\rangle$ matrix material.

After $10 \%$ recrystallization the recrystallized grains in steel K2. had the orientations $\{111\}\langle u v w\rangle$ and were growing into either similar material misoriented by a rotation of $10-20^{\circ}$, or $\{100\}\langle u v w\rangle$ 


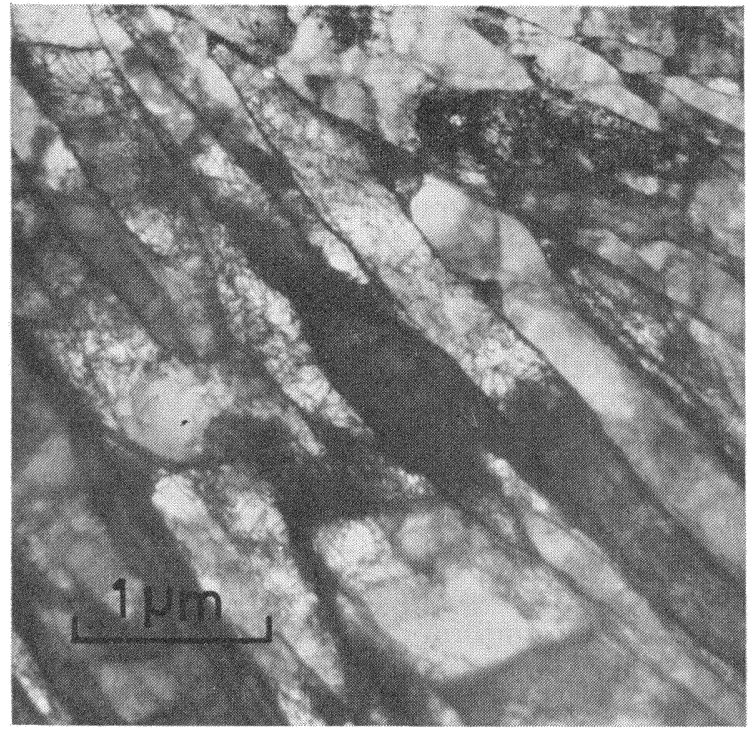

(a)

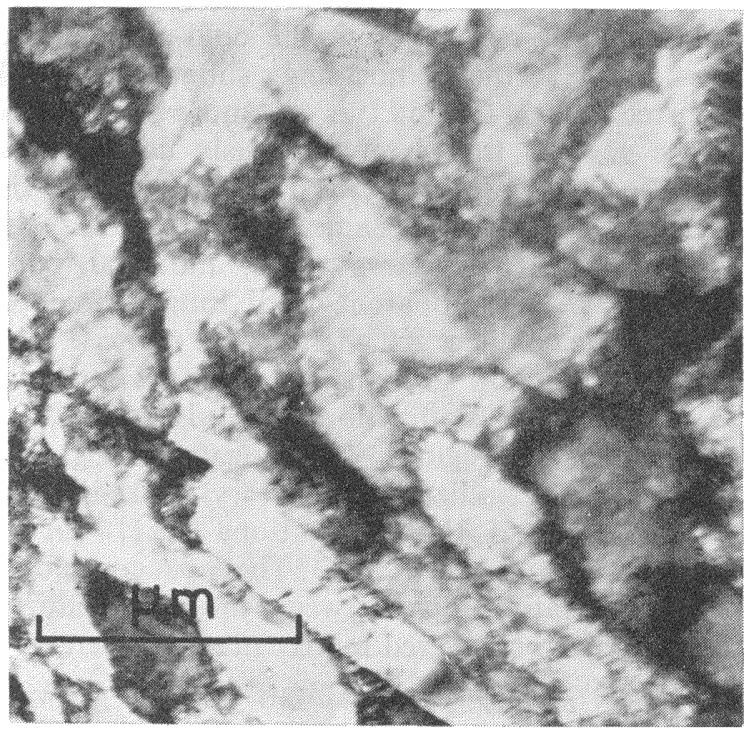

(c)

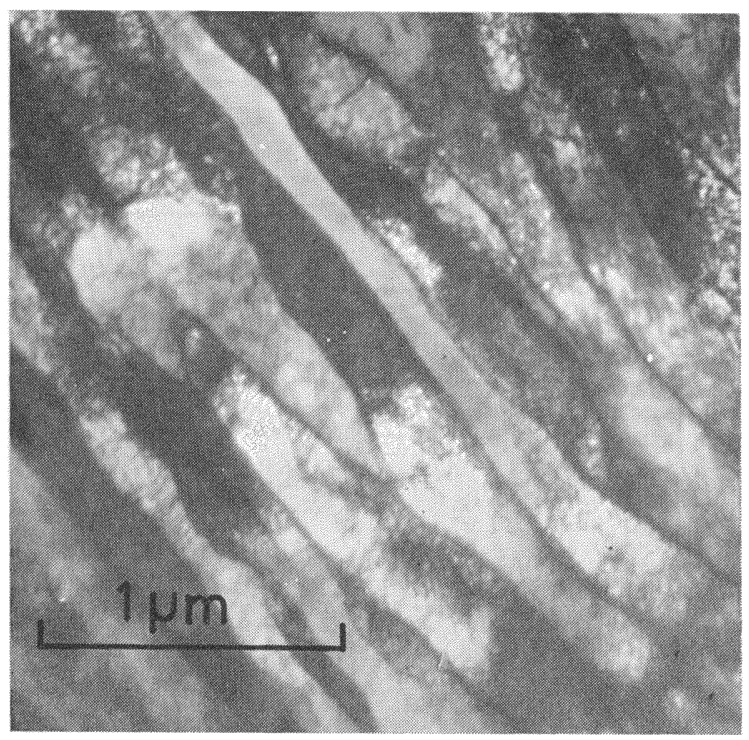

(b)

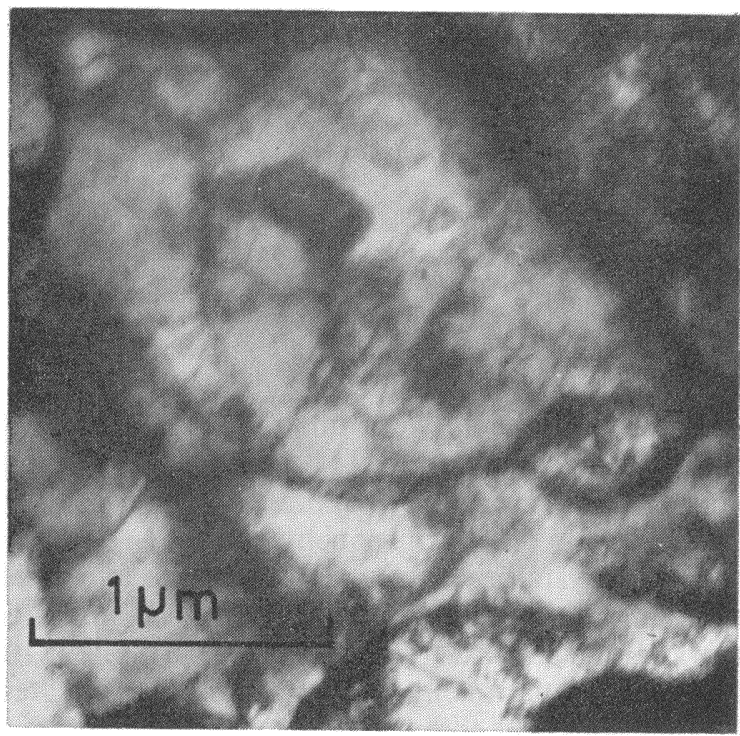

(d)

FIGURE 6 Typical Electron Micrographs showing the form of the substructure in the cold-rolled steels: $(a)$ Steel C2, TD section; (b) Steel K2, TD section; (c), (d) Steel K2, RD section. 


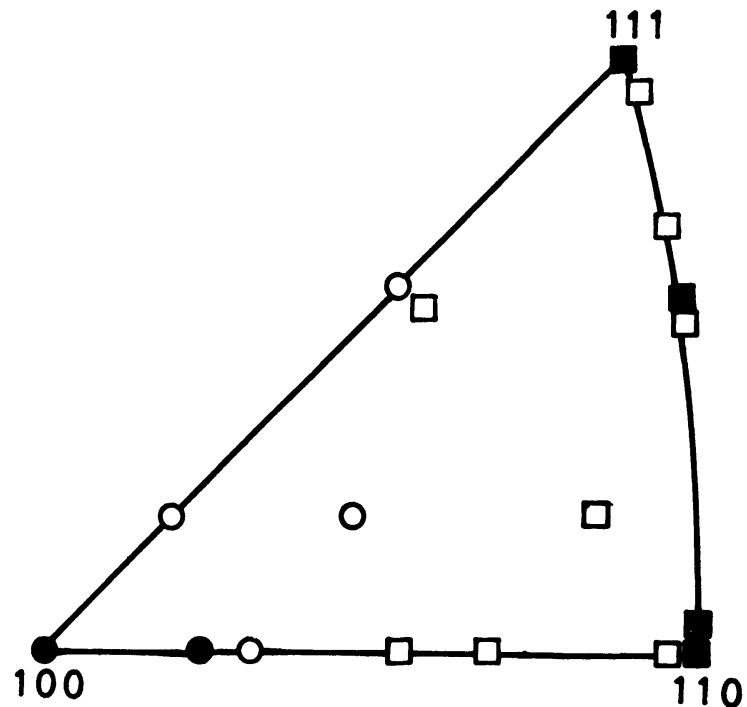

(a)

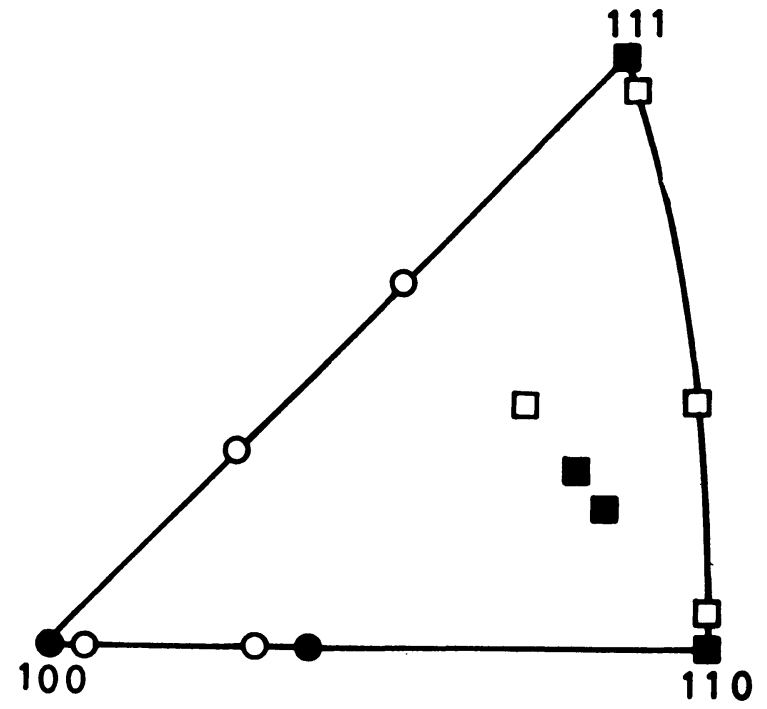

(b)

FIGURE 7 Orientation dependence of cell (subgrain) type in steels C2 (open symbols) and K2 (closed symbols), $(a)$ as cold rolled, and $(b)$ after recovery treatment at $500 \mathrm{C}^{\circ}$ : circles-equiaxed cells; squares-elongated cells.

matrix material. In steel $\mathrm{K} 2$ precipitates of aluminium nitride (AIN) were observed within the recrystallized grains. The precipitate particles defined a network that was similar to that of the prior subgrain boundaries; no precipitation was evident within the recovered matrix material.

\section{DISCUSSION}

\section{Cold-Rolled Steels}

Coexisting elongated and equiaxed cells of the type shown in Figure 6 have not been reported previously in edge foils. Elongated cell structures have been observed $^{20,21}$ in edge sections of cold-rolled steels and Embury et $a .^{20}$ reported that these were 0.4 $\mu \mathrm{m}$ thick and had an average length of $0.85 \mu \mathrm{m}$, i.e. approximately twice as large as the elongated cells observed here. Although there is no previous report of equiaxed cells in edge sections Goodenow ${ }^{22}$ has observed two types of cells in face sections:

i) slightly elongated cells $0.5-1.0 \mu \mathrm{m}$ in diameter;

ii) approximately equiaxed cells $1.0-2.0 \mu \mathrm{m}$ in diameter.

He was unable to relate the cell type to orientation.

The observation of a relationship between cell morphology, orientation and elastic stored energy is obviously significant to the understanding of

TABLE III

Stored energy of cold-rolled steels

\begin{tabular}{|c|c|c|c|c|c|c|}
\hline \multirow{4}{*}{$\begin{array}{l}\text { Component } \\
\{h k l\} / / R . P .\end{array}$} & \multicolumn{2}{|c|}{ Present Work } & \multicolumn{4}{|c|}{ Results of Matsuo et al. ${ }^{3}$} \\
\hline & \multirow{2}{*}{\multicolumn{2}{|c|}{$\mathrm{V} \mathrm{cal} / \mathrm{g}$ atom }} & \multicolumn{4}{|c|}{$\mathrm{V}$ cal/g atom } \\
\hline & & & \multicolumn{2}{|c|}{ Published Values } & \multicolumn{2}{|c|}{ Corrected Values } \\
\hline & $\mathrm{C}^{*}$ & $\mathrm{~K} 2 *$ & $\mathbf{A} \dagger$ & $\mathbf{B} \dagger$ & A $\dagger$ & $\mathbf{B} \dagger$ \\
\hline$\{110\}$ & 3.51 & 3.23 & 29.8 & 36.9 & 7.02 & 8.74 \\
\hline$\{111\}$ & 2.09 & 2.09 & 20.6 & 21.3 & 4.89 & 4.97 \\
\hline$\{211\}$ & 1.27 & 1.62 & & & & \\
\hline$\{100\}$ & 1.14 & 1.15 & 9.2 & 9.2 & 2.32 & 2.32 \\
\hline
\end{tabular}

*Sample C2 had an initial grain size of $145-150 \mu \mathrm{m}$ and was cold-reduced $70.6 \%$; sample $\mathrm{K} 2 \mathrm{had}$ an initial grain size of 35-40 $\mu \mathrm{m}$ and was cold-reduced $63.5 \%$

$\dagger$ Samples A and B are capped steels (70\% cold-reduced) with initial grain sizes $300 \mu \mathrm{m}$ and $30 \mu \mathrm{m}$ respectively 
annealing processes in rolled low-carbon steels, but before discussing this it is pertinent to examine first the meaning of the stored energy measured by $\mathrm{X}$-ray line broadening techniques.

The only comparable results are those of Matsuo et $a .^{3}$ and their results are given in Table III together with those obtained here. It is believed that Matsuo et al. made an error in their calculations of elastic stored energies $\dagger$ and recalculated values are also shown. The orientation dependence of elastic stored energy is identical in the two investigations, but the corrected energy values obtained by Matsuo et al. are still greater by a factor of 2-3. This discrepancy arises because Matsuo et al. used an X-ray diffraction technique, similar to that employed previously by Takechi et al. ${ }^{2}$ in which the particle size of the cold-rolled steels was assumed to be nearly equal to the cell size and large enough to make little contribution to line broadening. In agreement with results obtained by $\mathrm{Hu},{ }^{14}$ the present work indicates that the particle size is considerably smaller than the cell size and contributes to line broadening; this would account for the higher energy values obtained by Matsuo et al. The particle size of $300-500 \AA$ obtained here corresponds quite closely with the dimensions of the dislocation networks and substructures within the elongated cells.

The stored energy values are considerably lower, however, than the calorimetric measurements of Taoka et al. ${ }^{23}$ who found that the energy stored in $85 \%$ cold-reduced electrolytic iron was $101 \mathrm{cal} / \mathrm{g}$ atom. Similarly, Averbach et al. ${ }^{24}$ found that the elastic strain energy, determined from a Fourier analysis of X-ray line broadening, was only 3-4\% of the total energy stored in a $75 \mathrm{Au}-25 \mathrm{Ag}$ (wt \%) alloy deformed by filing. They concluded that the majority of the stored energy was associated with the cell walls in the deformed material and that the strains associated with the individual dislocations composing these walls were not detected by the $\mathrm{X}$-ray technique; this implies that only dislocations within the cells contribute to the observed elastic strains. Dillamore et $a l .{ }^{1}$ have also estimated the

$\dagger$ Matsua et al (3) evaluated stored energy from the expression $\mathrm{V}=3 / 2 \mathrm{Ee}^{-2}$. Their published data for $\mathrm{V}$ and $\overline{\mathrm{e}}^{2}$ would have required the following values of Young's modulus; $E_{111}$ $=1.2 \times 10^{13}$ dynes $/ \mathrm{cm}^{2}, \mathrm{E}_{110}=9.4 \times 10^{12} \mathrm{dynes} / \mathrm{cm}^{2}$, $\mathrm{E}_{100}=5.5 \times 10^{12}$ dynes $/ \mathrm{cm}^{2}$. Boas and Mackenzie ${ }^{(12)}$ give: $\mathrm{E}_{111}=2.84 \times 10^{12}$ dynes $/ \mathrm{cm}^{2}, \mathrm{E}_{110}=2.21 \times$ $10^{12}$ dynes $/ \mathrm{cm}^{2}$, and $E_{100}=1.32 \times 10^{12}$ dynes $/ \mathrm{cm}^{2}$. The latter values were used to obtain the corrected values in Table III. stored energy in $70 \%$ cold-rolled iron and lowcarbon steels. They assumed that the energy is concentrated in the cell walls and used electron microscope estimates of subgrain size and misorientation to calculate the stored energy of the various components of partial fibre texture $A$. The orientation dependence and the value of stored energy $(4.5 \mathrm{cal} / \mathrm{g}$ atom) were similar to those reported here. If their analysis is modified to take

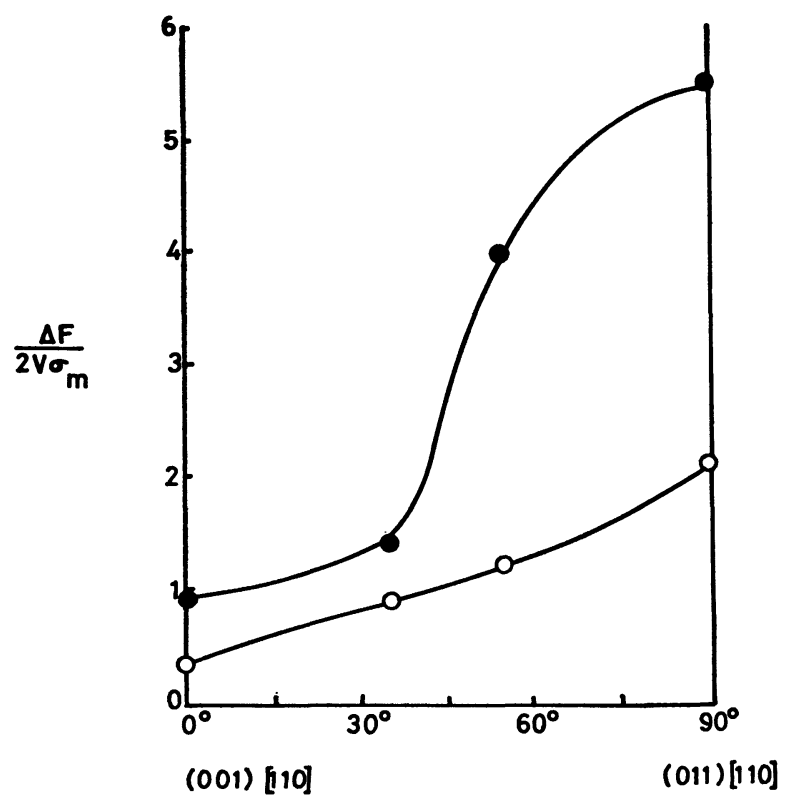

FIGURE 8 Variations in stored energy with orientation: open circles, results of Dillamore et al. ${ }^{1}$; closed circles, present results.

account of the cell dimensions observed in the present edge sections the orientation dependence of stored energy is unaffected but the mean value of stored energy is increased to $12.5 \mathrm{cal} / \mathrm{g}$ atom, Figure 8. This modified value is considerably greater than the present mean value of elastic stored energy $(1.85 \mathrm{cal} / \mathrm{g}$ atom) and further supports the view ${ }^{24}$ that elastic stored energy measurements derived from X-ray line broadening data do not include the energy associated with the dislocations in the cell walls. It should not be thought, however, that the measurements are entirely independent of cell wall contributions. It has been proposed $^{25-27}$ that long range elastic stresses are associated with the cell walls and the existence of such stresses has been suggested by several investigations. $^{20,21,28-30}$ The recovery behaviour of 
steels $\mathrm{C} 2$ and $\mathrm{K} 2$ discussed below indicates that both the elastic strains of the dislocations within the cells and the long range elastic stresses associated with the cell walls contribute to the elastic stored energy.

The data shown in Table III show that both the orientation dependence and the magnitude of elastic stored energy in cold-rolled steels depend on the prior grain size. The energy difference between the $\{110\}$ and $\{100\}$ components, $V_{110}-V_{100}$, decreases as the prior grain size is reduced and contradicts the results of Matsuo et al. ${ }^{3}$ The present results do not indicate the effect of grain size on the magnitude of elastic stored energy because different rolling reductions were used for steels $\mathrm{C} 2$ and $\mathrm{K} 2$ but the results of Matsuo et al. show higher stored energy values in smaller grain size material.

\section{Recovery}

The initial stages of recovery during annealing at $500^{\circ} \mathrm{C}$ are marked by a gradual reduction in the dislocation density within the cells, a rearrangement of the dislocations in the cell walls to form subboundaries, and a marked reduction in X-ray line broadening (Figures 4a, 4b). As other investigators ${ }^{1,3,31-33}$ have found, these changes occurred more rapidly in the high energy $\{110\}$ and $\{111\}$ components than in the lower energy $\{211\}$ and $\{100\}$ components. Two factors contribute to this reduction, the increase in particle size and the decrease in inhomogeneous strain (elastic stored energy) (Figure 5). During recovery at $500^{\circ} \mathrm{C}$ the particle size increased gradually to about $1000 \AA$, consistent with the gradual elimination of the dislocation substructure within the cells during subgrain formation. After subgrain formation was complete, however, the particle size was still considerably smaller than the cell dimensions indicating that removal of the substructure was still incomplete. Some $60-80 \%$ of the elastic stored energy had been released by the time subgrain formation was complete and there was a greater release from the high energy components than the low energy components (Figure 5). Electron microscopy and hardness measurements indicate, however, that this large release of elastic stored energy is achieved without any pronounced decrease in total dislocation density. Similar decreases in elastic strain and/or energy without detectable changes in dislocation density have been reported by others. ${ }^{14,24,30}$ Rapid recovery of flow stress with littlechange in dislocation density has also been observed. ${ }^{20,21,28,29}$
Dislocation annihilation processes alone cannot account for these changes and it seems that dislocation rearrangements involving relaxation of the long range elastic stresses associated with the cell walls must also contribute to the elastic strain energy. An appropriate model for the relaxation has been devised by $\mathrm{Li}^{25,26}$

Although similar structural changes were observed in both steels, the line broadening measurements (Figure 4) indicate that subgrain formation is inhibited slightly in steel K2. Inhibition has also been reported by Michalak and Schoone ${ }^{15}$ and by Dillamore and Fletcher ${ }^{34}$ who attributed the effect to the locking of dislocations by atmospheres of aluminium and nitrogen. Jolley, ${ }^{35}$ however, did not detect any inhibition of subgrain formation in aluminium-killed steels. After subgrain formation was complete there was no further change in the degree of line broadening until subgrain growth commenced and in this stage of recovery the two steels exhibited widely different annealing characteristics.

Capped steel, C2. In this steel subgrain growth occurred first in the high energy $\{110\}$ and $\{111\}$ components with an associated increase in particle size and a sharp decrease in elastic stored energy (Figure 5a). A similar orientation dependence of subgrain growth has been reported by Smith and Dillamore $^{31}$ who attributed the more rapid subgrain growth in the $\{110\}\langle 110\rangle$ and $\{111\}\langle 110\rangle$ orientations to three factors:

i) the smaller size and higher sub-boundary energy of these components and the consequent greater driving force for subgrain growth;

ii) differences in dislocation content of the subboundaries;

iii) differences in the subgrain size distribution of the various components.

The present work identifies another contributing factor, viz. the variation in cell morphology with orientation. An even greater advantage for growth is predicted for the $\{110\}\langle 110\rangle$ and $\{111\}\langle 110\rangle$ orientations than that given by Dillamore et al. ${ }^{1}$ (Figure 8). Furthermore, there is no equilibrium of sub-boundary tensions in elongated cell structures and the driving force for boundary migration would be greater than in equiaxed cells of comparable "size".

Aluminium-killed steel, K2. As observed previously ${ }^{15,34,35}$ subgrain growth in this steel was strongly inhibited for all orientations. X-ray line broadening measurements (Figure $4 \mathrm{~b}$ ) indicate that 
growth occurs first in the (111) component and that this is associated with a sharp decrease in elastic stored energy (Figure 5). Similar changes were not observed in the other components until longer times at temperature.

Although the supporting evidence has been of an indirect nature, the inhibition of subgrain growth in aluminium-killed steels has usually been attributed $^{1,15,22,36}$ to either pre-precipitation clustering, or precipitation, of aluminium nitride (AIN) during recovery at cold-worked grain boundaries and sub-boundaries. In the present work, the AlN particles within recrystallized grains were observed to delineate the prior substructure. The results indicate, however, that segregation of aluminium and nitrogen at sub-boundaries affects not only the absolute rate of subgrain growth but also the orientation dependence of subgrain growth. In particular, subgrain growth in the high energy $\{110\}$ components is inhibited to a greater extent than growth in the slightly lower energy $\{111\}$ components.

\section{Recrystallization}

The high energy $\{110\}$ and $\{111\}$ components were the first to nucleate in steel $\mathrm{C} 2$ and the incubation period was associated with the growth of elongated subgrains to the stage at which high-angle boundaries were formed. It is not known whether these subgrains had particular nucleation sites. Although the present work has shown that the high energy components recover and recrystallize more rapidly than lower energy components, the values reported are average values obtained from bulk material and do not describe the localized variations in strain energy in the various deformation texture components. Single crystal studies ${ }^{14,37,38}$ have revealed that transition bands within deformed crystals are the main source of these inhomogeneities of deformation and the preferred sites for nucleation. Transition bands can be formed by localised strain variations at grain boundaries and heterogeneous particles and also in homogeneous strain whenever the operative slip systems differ in different parts of a grain. ${ }^{39}$ In such cases the transition bands are geometrically necessary to accomodate the lattice rotations. Unambiguous transition bands were not observed in either of the steels used in this investigation. There are two possible reasons for this; the grain size was relatively small (145$150 \mu \mathrm{m}$ in $\mathrm{C} 2$ and $35-40 \mu \mathrm{m}$ in $\mathrm{K} 2)$ and the amount of deformation was not large $(\sim 70 \%)$. Neverthe- less, orientation variations were often detected across individual grains of the cold-worked steels and it seems reasonable to assume that undetected bands must have been associated with them. There can be little doubt, furthermore, that transition bands must separate the regions of elongated and equiaxed cells that were sometimes observed.

One of the most comprehensive analyses of the rotations occurring during the rolling of ferrite crystals is that of Dillamore et al. ${ }^{40}$ They showed that for crystals originally oriented with a $\langle 110\rangle$ transverse direction the so-called end orientations $\{111\}\langle 112\rangle$ and $\{110\}\langle 001\rangle$ are not stable and that rotation continues to $\{11,11,8\}\langle 4,4,11\rangle$. Several transition band orientations may be developed during these rotations and two of these, $\{110\}\langle 001\rangle$ and $\{111\}\langle 112\rangle$, are capable of growth into $\{11,11,8\}\langle 4,4,11\rangle$ matrix material. The present observation that nuclei having the $\{110\}$ and $\{111\}$ orientations grow into near $\{111\}$ matrix material is consistent with this analysis.

Nucleation was inhibited during annealing of steel $\mathrm{K} 2$ at $500^{\circ} \mathrm{C}$ and the nucleation frequency was reduced. The high energy $\{111\}$ components were the first to nucleate and recrystallized grains of these orientations grew into $\{111\}$ and $\{100\}$ recovered matrix material. The most significant difference between the recrystallization behaviour of the two steels was the marked inhibition of nucleation in the high energy $\{110\}$ components in steel $\mathrm{K} 2$. It appears that segregation of AlN has a greater retarding effect on the growth of these components than on the growth of $\{111\}$ components. No satisfactory explanation of this effect is apparent but there are two possible contributing factors:

i) the preponderance of $\{111\}$ matrix material increased the probability of growth under conditions of general subgrain growth inhibition;

ii) the high energy of $\{110\}$ components increased the probability of segregation at the subboundaries of these components.

It is interesting to compare the present results with the analysis made by Dillamore et al. ${ }^{1}$ of the recrystallization behaviour of low-carbon steels. Their prediction that grain boundary nucleation occurs first in the $\{001\}\langle 110\rangle$ component is not borne out and neither is the prediction that this component should grow at the expense of $\{110\}$ $\langle 001\rangle$ material. In fact nucleation began in the latter material. The suggestion that AlN segregation inhibits normal subgrain growth and permits orientation-selective nucleation of components 
close to $\{111\}\langle 110\rangle$ is verified. The assumption that nucleation at grain boundaries occurs by the bulge mechanism is not substantiated and this is the major source of the differences. If this assumption is not made, i.e. if it is assumed that nucleation occurs by subgrain growth only, the results are in good agreement with the predictions. It is now generally recognized that the role of transition bands in the nucleation of recrystallized grains (see above) makes the bulge nucleation proposals unnecessary.

\section{Textural Changes During Recrystallization}

It has been shown in the preceding sections that in steel $\mathrm{C} 2$ recovery and recrystallization occur most rapidly in the high energy $\{110\}$ and $\{111\}$ components and that, in the early stages of recrystallization, grains of these orientations grow at the expense of near $\{111\}$ matrix material. These observations are consistent with the initial increase in intensity of near $\{110\}$ components and the accompanying decrease in intensity of near $\{111\}$ components during annealing at both $500^{\circ} \mathrm{C}$ and $700^{\circ} \mathrm{C}$. It is apparent that textural changes during recrystallization must be determined primarily by considerations of oriented nucleation and that nucleation occurs in highly strained lattice regions. Dillamore et al. ${ }^{1}$ have discussed the role of oriented nucleation in texture formation but their prediction that $(100)\langle 011\rangle$ components develop at the expense of $\{110\}\langle 011\rangle$ material is not supported by the present results. The textural changes occurring at the surface of the sheet were the same as those at the midplane section (Figure 1b) and there was a marked decrease in intensity of partial fibre textures $\mathrm{A}$ and $\mathrm{C}$ and a marked increase in intensity of components near $\{110\}$.

At $500^{\circ} \mathrm{C}$ the textural changes in steel $\mathrm{K} 2$ were quite different to those in steel C2 (cf. Figures 1a, $2 \mathrm{a})$; there was an initial increase in the intensity of $\{111\}$ components and an accompanying decrease in the intensity of $\{100\}$ components. These changes continued during recrystallization and in the final texture, the $\{111\}$ components were much stronger than in steel $\mathrm{C} 2$. The increase was a direct result of the effect of AIN segregation on subgrain growth and nucleation in the $\{110\}$ components. Nucleation began in the $\{111\}$ components and subsequent growth occurred into both $\{111\}$ and $\{100\}$ matrix material but the marked inhibition of nucleation in the $\{110\}$ component prevented the development of this orientation at the expense of $\{111\}$ matrix material. Once again the textural changes are consistent with an oriented nucleation control of texture formation. At $700^{\circ} \mathrm{C}$, however, steel $\mathrm{K} 2$ recrystallized without appreciable segregation of AlN and at that temperature the textural changes in steels C2 and K2 were similar. Fibre texture C was the major component of the recrystallization texture in both steels and in the capped steel the intensity of this component was substantially independent of recrystallization temperature. In steel $\mathrm{K} 2$ the intensity of fibre texture $\mathrm{C}$ was much lower after annealing at the lower temperature. There was, nevertheless, a slight effect of annealing temperature in steel $\mathrm{C} 2$. The decrease in the intensity of the $\{111\}$ component was more marked at $700^{\circ} \mathrm{C}$ than at $500^{\circ} \mathrm{C}$ and the increase in intensity of the $\{110\}$ component at $700^{\circ} \mathrm{C}$ (8-fold) was greater than at $500^{\circ} \mathrm{C}$ (5-fold). The greater degree of recovery prior to recrystallization at $500^{\circ} \mathrm{C}$ apparently has a minor effect on the relative driving force for nucleation in the various components, particularly the high energy $\{110\}$ and $\{111\}$ components.

\section{Effect of Initial Grain Size on Recrystallization}

Because effects due to the segregation of AlN are insignificant during annealing at $700^{\circ} \mathrm{C}$ it is possible to examine the effect of prior grain size on the subsequent annealing behaviour. In both steels recovery and recrystallization occurred more rapidly in the high energy components and the overall textural changes were similar. It can be assumed, therefore, that these aspects of the annealing behaviour are independent of prior grain size. This assumption is supported by the results of Matsuo et al. ${ }^{3}$ with coarse-grained material (300 $\mu \mathrm{m}$ grain size) in which the $\{111\}$ component annealed more rapidly than the $\{110\}$ component but contradicted by their results for fine grained material ( $30 \mu \mathrm{m}$ grains size). Matsuo et al. devised a model which predicted that $\{111\}\langle 110\rangle$ components would develop adjacent to grain boundaries and predominate in fine-grained steels and that $\{110\}\langle 001\rangle$ components would develop within the body of relatively large grains. It was argued that local inhomogeneities, originating in grain boundary constraints, would enhance nucleation of $\{111\}$ components in the fine-grained steel even though the elastic stored energy of the $\{111\}$ components was less than that of the $\{110\}$ components. A logical consequence of this model would be a decrease in the energy difference 
$\left(V_{110}-V_{111}\right)$ with decreasing grain size; the opposite effect is observed (see Table III). Matsuo et al. also found that for small column lengths the lattice strains were higher in the fine-grained steel than in the coarse-grained steel and argued that there are two types of $\{110\}$ components, one slow to recover and recrystallize and the other a potential nucleus during annealing. Despite its contrived nature this model highlights a major deficiency of current energy determinations. There can be no doubt that the measured energy for the $\{111\}\langle u v w\rangle$ components includes contributions from many components, $\{111\}\left\langle u_{1} v_{1} w_{1}\right\rangle \ldots\left\langle u_{n} v_{n} w_{n}\right\rangle$, and it is logical to expect that these will have different values of elastic stored energy and particle size and that they could be distributed inhomogeneously within the grains. The identification of these components and measurements of their energy and particle size is a necessary step towards a real understanding of nucleation in annealing processes.

\section{CONCLUSIONS}

1) There is an orientation dependence of elastic stored energy in cold-rolled ( $70 \%$ reduction) lowcarbon steels and the sequence is

$$
V_{110}>V_{111}>V_{211}>V_{100}
$$

2) In capped steels the rate of subgrain growth and nucleation of recrystallized grains is related directly to the stored energy of the component and is greatest in the high energy $\{110\}$ and $\{111\}$ components; recrystallized grains of these orientations grow into near $\{111\}$ matrix material.

3) At temperatures $\leqslant 500^{\circ} \mathrm{C}$ precipitation and/or segregation of AlN at sub-boundaries inhibits subgrain growth and nucleation in aluminium-killed steels. Inhibition is greater in the high energy $\{110\}$ components than in the slightly lower energy $\{111\}$ components and recrystallization begins first in the latter. Recrystallized grains of this orientation grow into $\{111\}$ and $\{100\}$ matrix material. At temperatures $\geqslant 600^{\circ} \mathrm{C}$ aluminium-killed steels behave in a similar fashion to capped steels.

4) In the early stages of recrystallization oriented nucleation in highly strained lattice regions determines the range of orientations developed and influences strongly the primary texture.

\section{ACKNOWLEDGEMENT}

One of the authors (R.E.) acknowledges the award of a University of N.S.W. post-graduate scholarship.

\section{REFERENCES}

1. I. L. Dillamore, C. J. E. Smith and T. W. Watson, Met. Sci.J. 1, 49 (1967).

2. H. Takechi, H. Kato and S. Nagashima, Trans. Metll. Soc. AIME 242, 56 (1968).

3. M. Matsuo, S. Hayami and S. Nagashima, in Advances in $X$-ray Analysis 14, 214 (1971).

4. T. R. Thompson and J. M. Baker, J. Aust. Inst. Met. 14, 84 (1969).

5. T. R. Thompson, J. Aust. Inst. Met. 14, 329 (1969).

6. L. G. Shulz, J. Appl. Phys. 20, 1033 (1949).

7. G. B. Harris, Phil. Mag. 43, 113 (1952).

8. R. M. S. B. Horta, W. T. Roberts and D. V. Wilson, Trans. Metll. Soc. AIME 245, 2525 (1969).

9. A. R. Stokes, Proc. Phys. Soc. (London) 61, 382 (1948).

10. B. E. Warren and B. L. Averbach, J. Appl. Phys. 23, 497 (1952).

11. B. E. Warren, Met. Phys. 8, 147 (1959).

12. W. Boas and F. K. Mackenzie, in Prog. Met. Phys. 2, 90 (1950).

13. A. H. Lutts and P. A. Beck, Trans. AIME 200, 257 (1954).

14. H. $\mathrm{Hu}$, in Recovery and Recrystallization of Metals (Interscience, New York, 1963), L. Kimmel Ed., p. 311.

15. J. T. Michalak and R. D. Schoone, Trans. Metll. Soc. AIME 242, 1149 (1968).

16. P. N. Richards, J. Aust. Inst. Met. 14, 1 (1969).

17. S. R. Goodman and H. Hu, Met. Trans. 1, 1629 (1970).

18. I. F. Hughes, Met. Trans. 2, 929 (1971).

19. P. N. Richards, J. Iron and Steel Inst. 207, 1333 (1969).

20. J. D. Embury, A. S. Keh and R. M. Fisher, Trans. Metll. Soc. AIME 236, 1252 (1966).

21. M. J. Roberts and W. Jolley, Met. Trans. 1, 1389 (1970).

22. R. H. Goodenow, Trans. ASM 59, 804 (1966).

23. T. Taoka, K. Suzuki, A. Yoshikawa and M. Okamoto, Acta Met. 13, 1311 (1965).

24. B. L. Averbach, M. B. Bever, M. F. Comerford and J. S. H. Leach, Acta Met. 4, 477 (1956).

25. J. C. M. Li, J. Appl. Phys. 32, 1873 (1961).

26. J. C. M. Li, J. Aust. Inst. Met. 8, 206 (1963).

27. J. C. M. Li and D. C. Needham, J. Appl. Phys. 31, 1318 (1969).

28. A. S. Keh and S. Weissmann, in Electron Microscopy and Strength of Crystals (Interscience, New York, 1963), G. Thomas and J. Washburn Eds., p. 231.

29. A. S. Keh, in Direct Observations of Imperfections in Crystals (Interscience, New York, 1962), J. B. Newkirk and J. W. Wernick Eds., p. 213.

30. J. E. Bailey and P. B. Hirsch, Phil. Mag. 5, 485 (1960).

31. C. H. E. Smith and I. L. Dillamore, Met. Sci. J. 4, 161 (1970).

32. C. Dasarathy and R. C. Hudd, paper presented at the Deutsche Gesellschaft fur Metallkunds Hauptversaimmlung, West Berlin, May (1969).

33. H. Hu and S. R. Goodman, Met. Trans. 1, 3057 (1970).

34. I. L. Dillamore and S. F. H. Fletcher, in Recrystallization, Grain Growth and Textures (ASM, Metals Park, Ohio, 1966), p. 448.

35. W. Jolley, J. Iron and Steel Inst. 205, 321 (1967).

36. P. N. Richards, J. Aust. Inst. Met. 14, 1 (1969).

37. J. L. Walter and E. F. Koch, Acta Met. 10, 1059 (1962).

38. R. Jago, Ph.D. Thesis, University of N.S.W. (1971).

39. P. Morris, Private Communication.

40. I. L. Dillamore, E. Butler and D. Green, Met. Sci. J. 2, 161 (1968). 